\title{
Facebook - Face it or Phase Out
}

Musleha Nasmian, Saiful Farik Mat Yatin, Raihan Ismail, Syaiful Hisyam Saleh, Mohd Nizam Yunus, Azman Mat Isa, Mohd Jailani Paiman

To Link this Article: http://dx.doi.org/10.6007/IJARBSS/v10-i11/9074

DOI:10.6007/IJARBSS/v10-i11/9074

Received: 21 September 2020, Revised: 23 October 2020, Accepted: 19 November 2020

Published Online: 28 November 2020

In-Text Citation: (Nasmian et al., 2020)

To Cite this Article: Nasmian, M., Yatin, S. F. M., Ismail, R., Saleh, S. H., Yunus, M. N., Isa, A. M., \& Paiman, M. J. (2020). Facebook - Face it or Phase Out. International Journal of Academic Research in Business and Social Sciences, 10(11), 1483-1495.

\section{Copyright: @ 2020 The Author(s)}

Published by Human Resource Management Academic Research Society (www.hrmars.com)

This article is published under the Creative Commons Attribution (CC BY 4.0) license. Anyone may reproduce, distribute, translate and create derivative works of this article (for both commercial and non-commercial purposes), subject to full attribution to the original publication and authors. The full terms of this license may be seen at: http://creativecommons.org/licences/by/4.0/legalcode

Vol. 10, No. 11, 2020, Pg. 1483 - 1495

Full Terms \& Conditions of access and use can be found at http://hrmars.com/index.php/pages/detail/publication-ethics 


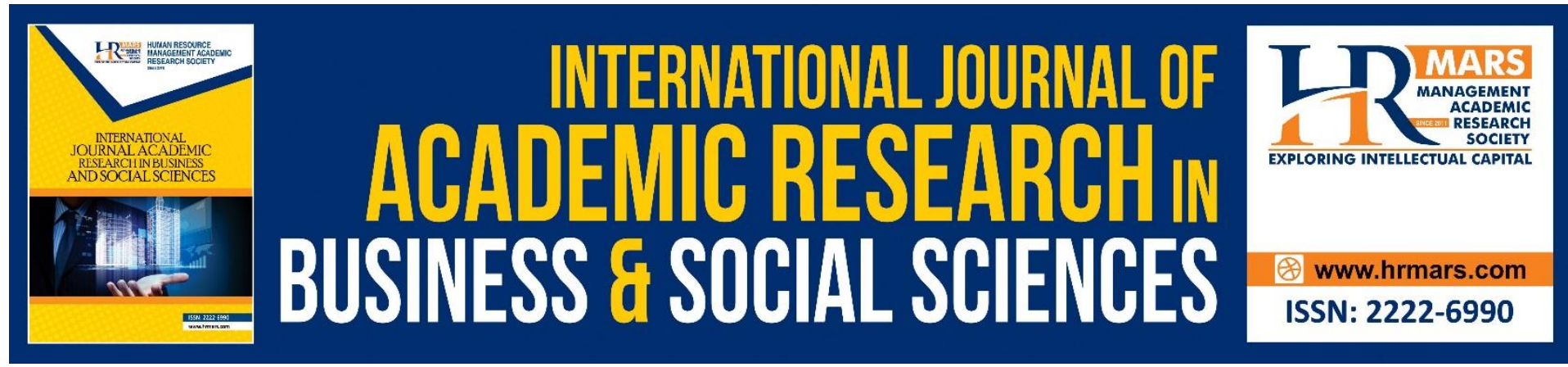

\title{
Facebook - Face it or Phase Out
}

\section{${ }^{1}$ Musleha Nasmian, ${ }^{2,3}$ Saiful Farik Mat Yatin, ${ }^{4}$ Raihan Ismail, ${ }^{5}$ Syaiful Hisyam Saleh, ${ }^{2}$ Mohd Nizam Yunus, ${ }^{2}$ Azman Mat Isa, ${ }^{2}$ Mohd Jailani Paiman}

${ }^{1}$ HICOM HBPO Sdn Bhd, Selangor, Malaysia, ${ }^{2}$ Faculty of Information Management, Universiti Teknologi MARA (UiTM) Selangor, Malaysia, ${ }^{3}$ Members of Advanced Analytics Engineering Center (AAEC), UiTM, Malaysia, ${ }^{4}$ Information Security Department, Celcom Axiata Bhd, Malaysia, ${ }^{5}$ PTAR, Universiti Teknologi MARA (UiTM) Negeri Sembilan, Malaysia Email: farik@uitm.edu.my

\begin{abstract}
Facebook users have been bombarded with the latest scandal of Cambridge Analytica and privacy breach which has become a major crisis of trust with the public. The respective Facebook founder, Mark Zuckerberg was summoned by the US Congress for two days hearing to state his defends. Social media has become a source of big data that can be manipulated or harvested mostly for marketing and social branding using sophisticated Artificial Intelligence (Al) and machine learning technology. This paper proposes a holistic reflection on the opportunities and risks brought about facing with or phasing out of the use of Facebook in Malaysia with the main aim of highlighting the need to acquire a new awareness of the possible unethical use of personal details, and potential that this data is being used to develop Al.
\end{abstract}

Keywords: Social Media, Facebook, Artificial Intelligence.

\section{Introduction}

Statistic shows there are over 3.7 billion people on the Internet. It is estimated that by the year of 2020, a total of 2.95 billion people will be active on social media, and these figures are expected to grow. Facebook is one of the most popular and widely used platforms of social media for people to connect with each other across the globe as well as to find and share information. In the third quarter of 2012, the number of active Facebook users had surpassed 1 billion, making it the first social network ever to do so. As of the fourth quarter of 2017, statistic shows that Facebook had a total of 2.2 billion monthly active users (Statista Research Department, 2020). On the other hand, going local, the population in Malaysia was 32.3 million in the fourth quarter of 2017. Studies by The Statista Portal show on the growth of the population possessing Facebook accounts from 2015 until 2018 were carried out and the result is, as depicted in the following bar chart. 


\section{Demographic Data of Malaysia}

Facebook has become a way of life in half of the population in Malaysia. It is a medium of interaction and for users to express their views; normally by projecting their happy moments.

Users make jokes, share stories, praise other users, give comments and constructive criticism, and sometimes make sarcasm remarks towards popular issues. It has also become a marketplace where Facebook users share the benefits of their products or services to attract other users for business purposes including up-selling and cross-selling of products and services. Transactions happen every day with Facebook users buying or selling goods.

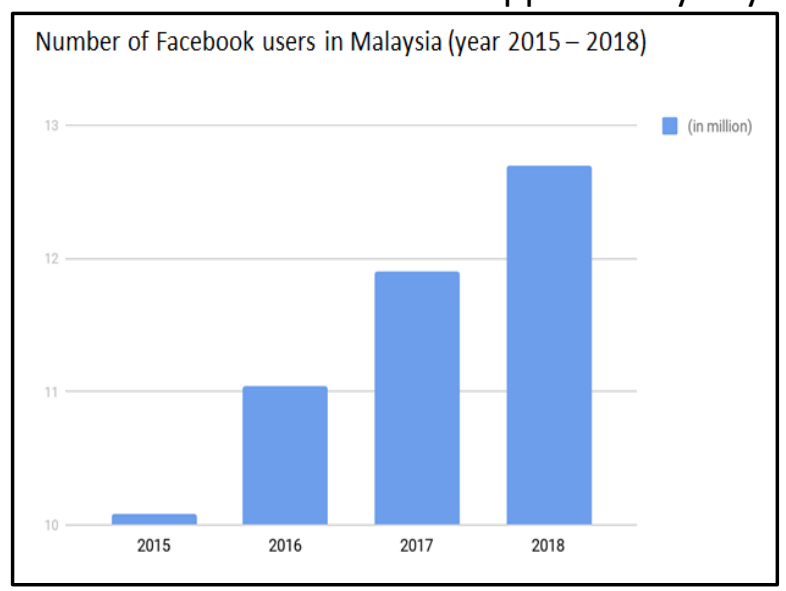

Figure 1: Facebook users in Malaysia

There are 16 million local business pages have been created as of May 2013 which is a 100\% increase from 8 million in June 2012 according to an article from zephoria.com. Malaysians' daily lives have been integrated into the social media, mainly Facebook, the minute they wake up from bed, in the car while waiting for their turns in the massive traffic jam, 10 minutes before they start working, during lunch breaks, and immediately after working hours have ended. It is obvious that almost every activity tends to be updated on the social media; hoping for some virtual friends to like the posting, leave a comment or even share their posts, especially those that furnish latest insights related to interesting current issues or become trending and viral.

Recently, the world was awakened by the breaking news of a Facebook scandal involving the Facebook founder himself. The data mining and analytics company based out of London had gained access to data on as many as 50 million Facebook profiles as a result from the data-sharing policies that Facebook application developers created back in 2014. This data, which was sold to Cambridge Analytica against Facebook's terms of service, reportedly informed the firm's election advertisement targeting toolset used by the campaign of President Donald Trump and others. The fallout was severe, involving numerous lawsuits, governmental inquiries, a \#DeleteFacebook user boycott campaign, and a significant drop in share price that had erased nearly $\$ 50$ billion of Facebook's market capital. Another thrilling prediction by the late Stephen Hawking according to Kharpal (2017) about Artificial Intelligence (Al) is extremely worrying and this can relate to the current issues discussed on Facebook.

This article will discuss the Facebook phenomenon happening in Malaysia, the concerns among its users, as well as the risk of data breach involving personal data. 


\section{Social Media Issues \\ Manipulation of data mining}

The process to extract data from its sources is called data mining. In order to produce useful information and statistic, some formulation is used by the developer so that the analysed data means something for their client. The manipulation will benefit users in term of business decision, marketing strategy, and sadly it is now widely used as a medium for agenda-setting and political propaganda to influence users. In the background, Facebook virtual agent is collecting all the data of user's behaviour when they select an emoticon instead of only selecting 'likes'. This information is very useful to develop an Al so that it can be as close as human interaction especially when it has to handle people with fragility like elders and people with critical illnesses.

\section{Big Data Issue}

Information on social media is not reliable. It has been flooded with fake news, false information, hate speech, sarcasm, trolling, hoax, emotion, and unresponsive manner. Facebook should not be used as the source of genuine information, especially to couple it with the technology of Artificial Intelligence (AI) - refer to Stephen $\mathrm{H}^{\prime}$ s prediction. The late Stephen Hawking made a prediction that Artificial Intelligent (Al) will be a new form of life that will outperform human in the future. Although he did not specify a timeline for his predictions, people still hear his words, "The genie is out of the bottle. I fear that Al may replace human altogether."

This concern has risen over the basis that Al has been developed from the source of big data like social media. Examples of the types of information that have exploded throughout the world that has no boundaries are sentiment analysis, opinion mining, emotion detection, identifying hate speech, monitoring data collection, sarcasm, propaganda, misinformation, viral hoax, human bias, prejudice, and stereotype.

How is the data been collected? It is collected from posting, comments, and responsive manner from Facebook user by a Virtual Agent. Then the raw data gets processed by a powerful tool like Natural Language Processing (NLP). If the Al is going to evolve, which behaviour will it take? How is the Al going to respond to threats? These questions generate a lot of possible answers and users will not like most of it. Probability, scenarios shown in science fiction movies like 'The Matrix', 'I am Legend', and 'I Robot' were some of the few examples of how our future would be.

\section{Risk of Exposing Sensitive Data}

It will be a disastrous event for an organisation to deal with a case of data breach. The impact may cause financial penalties, losing customers' trust and confidence, as well as criminal charges. IBM (2017), stated that since 2013 there was a 29\% increase of data breach incident which recorded a $\$ 4$ million of total cost on average. This concern raised the following questions - How to limit data exposure or leaks? How to protect sensitive data? How to ensure that data remains protected from falling into the wrong hands? The matter of privacy issues, sensitive data, personal data, and possibility of a threat to National Security are some of the potential risks that should be considered by any country. This also includes unethical use of data - including whether data is shared with or sold to other third-parties such as CubeYou and Aggregate IQ without consent.

Kumar (2017) who is one of the contributors in IDG Contributor Network, in his article stated that the average cost per record is $\$ 158$ whereas the cost per record breached ranges from 
$\$ 355$ to $\$ 129$ for healthcare and retail industries respectively. Despite the high risk of threat, enterprises continue to fall victim to data breaches globally and it raises a significant concern over protecting the data that organisations possess, process, and store. He also stated that while the external threats remain highly potential, the threat to sensitive data is also from insiders. He also lined up an example of an employee stealing customers' information, personally identifiable information (PII) data, or credit card details, is due to the fact that in most cases, privileged users like system administrators or database administrators are given authorised access to the data. Often the real data from the production environment is copied over to the non-production environment which is less secure and not managed with the same security controls like the production; resulting data can be exposed or stolen.

A court case between Lucy Gerena as the plaintiff with Facebook, Inc. as the defendant, Facebook has been accused of providing data needed by Cambridge Analytica, a data firm to help Donald Trump without getting the Facebook users' permissions and informed consent. The case also stated that this is not the first time that Facebook has allowed thirdparty apps to steal personal information without permission or informed consent. Facebook has confirmed that about 87 million Facebook users have been affected.

Apparently, this is not the first time Facebook has allowed personal information stolen by third-party without informed consent before the Cambridge Analytica scandal. Companies like Aggregate IQ and CubeYou have also been harvesting this data and selling it for few years back. They boast on their websites of how much data they have been collecting. Damage has been done and unethical collected data has gone. Facebook did nothing of this situation until they have been caught red handed. When personal information is taken, this may expose users to identity theft.

\section{Internet for Advertisements}

Facebook admits that the site tracks users around the Internet for advertisements. Facebook site was said that it continues to track people even if they have logged out from the site or they are not even Facebook users. In February 2018, a Belgian court ruled that Facebook had violated the European privacy law with such tracking activities as it had not obtained consent either to collect or store the data. The site was said that it even tracks people who do not actually use it and are not logged in it. The admission, which reveals new information about how exactly Facebook watches its users, is revealed in a blog post published by the site's product management director, David Baser.

During questioning from US politicians in April 2018, Mark Zuckerberg seemed unclear on the specifics of Facebook's tracking and suggested that data was mainly collected to ensure that Facebook was kept safe. It was said that the tracking was for three main reasons, which include providing its own services within Facebook, making sure the site stays secure and the system is not abused, and enhancing Facebook's own products and services; a category that includes tracking for advertisements.

Detailed information was then furnished by Baser about the way the tracking works for each of the main reasons mentioned earlier by Griffin (2018) revealed that Facebook is tracking people as they browse through other sites on the Internet - something that has been vague in the way Facebook has described its own tracking. Baser explain that when someone visits a site or application that uses Facebook services, Facebook receives information even if the person has logged out from Facebook or do not even have a Facebook account. The reason behind is other applications and sites do not know who is using Facebook. 
Further investigation revealed that Facebook collects data on people's online habits. It pays third-party websites and applications in order to let it embed tracking code in Internet browsers and mobile devices across the Internet; such as 'cookies', invisible screen pixels, or Facebook's 'like' and 'share' buttons. The code is designed to report back to Facebook on people's behaviour which is browsing habits, in order to help Facebook obtains better target advertisements. Reuben Binns, an Oxford University computer scientist who researches these phenomena, along with Google, Facebook is among the top three data-collectors in the Internet industry.

An article in Facebook Hearings (2018) mentioned that Facebook users have the option to choose to turn off the collection of data for advertising purposes. However, the fact is there is no such setting on Facebook that users can limit advertisement targeting, but this requires several steps which users may have to repeat from time to time. By default, Facebook shows users related advertisements which are based on interests that users' expressed over the years and the companies the users have interacted with; for instance, by sharing users' emails or telephone numbers, visiting their websites or using their applications. Users can turn off such targeted advertisements with a single option in users' Facebook settings. By doing so, users will not receive an advertisement on Facebook on the products or services they have looked through on a shopping website.

However, this does not stop the data collection. Facebook also adds targeting categories based on users' demographic information, such as users' birthday, age, gender, mobile devices they use, and even users' political leanings, regardless users have explicitly shared the details on Facebook or not. For that, users are required to visit the settings from time to time and select them one by one in settings. If users like or follow a new page, click on a new advertisement or add email address to a new business' contact list, the setting should be revisited to ensure proper control is adequately applied.

\section{Technology in Facebook: Facial recognition}

Facial recognition technology used in Facebook has caused the Facebook founder to face lawsuit. It is known that Facebook looks through uploaded pictures and tries to spot users in them, which is called tagging. 'Tag suggestions' provides a feature that suggests people to tag after a Facebook user uploads a photo or video. However, with this capability, Facebook was claimed that it was using facial recognition on people's photos without their consent and this has caused the Facebook founder to face legal actions.

The situation gets worsened by the wide range of privacy and data abuse scandals since it was proven that the platform had been providing users' data to developers without them knowing. This has led to a new range of scrutiny, including people started to realise that Facebook appears to be tracking their telephone calls and messages as well.

\section{Criteria}

Ideally, Facebook is the platform for connecting people worldwide. It enables its users to stay in touch with family members, friends and not forgetting making new acquaintances, friendships and building relationships. With its instant messaging and video chat features, the status updates, photos and profile information, Facebook provides a perfect environment to stay connected and updated on the happenings and important events.

Facebook enables its users to voice out and express themselves openly by updating status updates, sharing the up and down moments of their lives with pictures and videos and commenting on other users' posts. People with the same areas of interest can use it to 
exchange ideas and share their experiences, challenges and knowledge thus enhancing the information at hand which helps in their careers and personal lives.

\section{Facebook is Integrated in Daily Lives}

For millions of Malaysians, Facebook has become the way of life. It is a way of social stimulation that the interesting activities of their everyday lives. To say "no" to Facebook is easier said than done, especially many of Malaysians generations are socially addicted, and even for education, professional or even politics will do their interactions on web-based content as such Social Networked Site (SNS) like Facebook. Facebook has many positive factors like sharing photos, writing on Facebook walls, accessing to upcoming social events and increased contact with old friends and other potential friends, it also forces people to fixate and obsess over their digital image taken from an article by Theising (2011) in Facebook Has Become an Integral Part of Life, Daily Trojan.

Most of the Facebook users show themselves as they want others to see them. People list their music tastes, post photographs from their activities such as birthday party, food and drink in the restaurants, vacation or even petty thing such as queue number in bank or post office and post motivational quote to build a digital persona that will portray a favourable image to family, colleagues, and friends that they do not even know personally but are friends in Facebook. It gives the idea that user is always happy with their daily lives and also having fun based on their posts. These false perceptions will not necessarily make them happy. The reality is that most of them spend many of their time alone, either by choice or because they have to finish their work and chores.

People love to shop and before the existence of Facebook had been introduced by the commerce websites as such Amazon.com, eBay and many other e-commerce shops. Facebook ideally is integrated with our daily lives when shopping using Facebook has been one kind of trend for the billions of users in Facebook; and Malaysians also use Facebook to sell and buy goods and services. The issue here is the trust to be put in the sellers, and due to the many complaints lodged by the Facebook users in Malaysia, sellers need to register their online businesses with Companies Commission of Malaysia. People who wish to buy products in Facebook Online Business can rest assure and feel secure with the transaction they will commit with the product they buy from Facebook.

Despite the positive aspects Facebook can offer to the SNS users, there are still many other negative aspects experienced by Facebook users.

First of all, Facebook as a platform for the marriage institutions get involved with scandals by the husbands or the wives. A study was conducted by the American Academy of Matrimonial Lawyers (AAML) in 2015, a dramatic $97 \%$ of members have seen an increase in divorce evidence being taken from smart phones and other wireless devices during the past three years. In addition to that, an almost universal number of $99 \%$ of respondents have cited a rising number of text messages being used in cases, while $67 \%$ have noted more evidence being gathered from apps. As might be expected, the top three apps for divorce evidence also mirror popular social media sites, with $41 \%$ citing Facebook, $17 \%$ choosing Twitter, and $16 \%$ noting Instagram. The study stated that the main factor of the divorce cases is increased due to the existence of a third-party and the communication with the exes in their relationships. Another factor is that the jealousy between both husbands and wives really concerning because when the husbands or the wives looked to their partners' messages that can be suspicious which is discussing on sensitive matters, feeling issues and 
even sex. This will increase jealousy and rage, eventually leading to a divorce as the only way out. Mohd Alif Mohd Nawi and Mohd Isa Hamzah (2010) mentioned Sheikh Egypt Abdel Hamid al-Atrás, the former Head of Fatwa Commission at the prestigious Al-Azhar University, has issued the fatwa that said such sites referring to Facebook has become the factor in the increased rate of the marital infidelity. While one of the spouses is at work, the other is chatting online with someone else, wasting their time and can occur scandal with the third-party. The fatwa came after a study had been conducted and resulted that every five cases of divorces in Egypt were caused after one of the partners started using SNS such as Facebook.

Another negative aspect of using SNS such as Facebook is that users can become addicted. Facebook addiction can be defined as spending excessive time. Its involves a person's which is interfering with important activities in life; such as work, school, and many other factors taken from an article by Walker (2018) stated that, in order to reduce this addiction, the suggestion is the person who is addicted to SNS such as Facebook needs to delete or deactivate the account in order to control their excessive use. Whenever they spend most of their time on Facebook, they will ignore their main purpose of living. For example, a student needs to study but if the addiction towards Facebook is increasing it will affect their study and eventually give bad marks.

In short, the use of SNS in daily lives has become integral because of the sophisticated technology already becoming a must-have in our lives. But, Facebook users need to be sure and careful while using Facebook to ensure that they are not stray away from the meaning of life which consists of socialising with people and the respects and ethics with people in the SNS such as Facebook.

\section{Discussion}

With the raising concerns that have been discussed in the above, this has raised a question - Should Facebook be banned?

The breach of privacy and personal details are matters of trust. The data collected from Facebook posted by users may not possess as threat at first. But the users may not realise they have exposes themselves to a greater risk. The number of pictures and words that are posted numerously every day for several years has become as what they call as big data. A junk for one person but a gold mine for others. Information has now become a valuable commodity that can be beneficial for many.

Users' trusts have been breached, security has been compromised. Most of us believed that Facebook has stolen our information but they keep posting or read other posting every day. Most of us are narcissists and love to speak about ourselves which some may call as attention seekers. Many suicidal cases were related to cyber bullies in social media. There are too many cases where people are getting bullied on this site, people are getting depressed, and some even take their own lives, it has caused marriage break ups, fights, arguments, stress, paranoia, and in general runs many people down. This recent phenomenon raises a national concern and many people has spoken about this including celebrities. A campaign for ethical use of social media has been widely posted by many people. A lot of people have decided to disconnect from social media to support the cause. Nevertheless, it does not stop everybody especially for people who rely on social media to generate income, especially in today's competitive world and cost of living getting increased daily. Data driven for decision making plays an important role and increase the demand to 
process a large amount of data. Business requires a future prediction in various domains so as to gain competitive advantages.

Social media no longer serves the sole purpose of individual to express her/his own thoughts and opinion (in various topic such as such as Political, Business, Medical, Education), but as a gold mine of knowledge and power.

\section{Should Facebook be Banned?}

So, let us consider both the pros and cons. Facebook is a great site for increasing knowledge, connecting with family and friends, improving communication skills and sharing of thoughts and beliefs. On the other hand, people may misuse it and spread negativity through it. It can also lead to waste of time as people tend to become addicted to Facebook. However, that solely depends on the individuals themselves.

Nevertheless, Facebook is not the only site with such benefits, there are many other sites. But just like Facebook, every other site can be misused. That does not mean that every site should be banned. Sure, Facebook contains inappropriate stuff and can be a waste of time, but that is not Facebook's fault instead the individuals. Due to this argument, people disagree when others are blaming Facebook. Thus, it should not be banned. However, other side of the world has taken serious actions to protect the country and citizens from being negatively impacted by social media.

\section{Facebook users' Responsibilities}

It is always one's personal decision based on own judgment, to be part of the social media; and this includes Facebook. As a user, everyone should play their roles in ensuring that they are being responsible to what they can control. They can opt to continue being a Facebook user, and practice the safer way of using the system as well as apply necessary controls to ensure tighter security of their own data or can simply opt to discontinue being one.

When it comes to national security, the leader of the country has the right to decide what is best for the country. For instance, China has banned major websites of social media, Apps, search engines, work tools, and media sharing by blocking them from being accessible by the citizens. Just to name a few, these major websites include Facebook, Twitter, Instagram, Pinterest, Tumblr, Snapchat, Google+, WhatsApp, Telegram, Google, Yahoo, YouTube, Google Drive, Gmail, and Dropbox. Besides China, Indonesia has recently threatened to block Facebook from the country as well.

The least that Facebook users should do is to revisit their Facebook's security and privacy settings from time to time and ensure to allow only what is necessary to help protect their own accounts and privacy.

\section{Best Practise for Facebook users}

What Facebook users should do to stop Facebook from revealing everything about them? Despite the fact that Mark has finally apologised and claimed responsible, Facebook users should also play their roles as responsible social media users, by taking the following steps as control measures:

1) Lock down Facebook profile

To do this, In Facebook 'Settings', select the 'Privacy' tab. From here, users can control who gets to see their future posts and friends list by choosing either 'Public', 'Friends', 'Only Me' and 'Custom' in the dropdown menu.

2) Limit old posts 
Even though when this setting is changed, there will be no effect on who is able to see past Facebook posts. Instead, on the 'Privacy' page, users have to click on 'Limit Past Posts', then select 'Limit Old Posts' and finally hit 'Confirm' on the pop-up.

3) Be less visible and harder to find

Facebook users can stop random people from adding them by selecting 'Friends of Friends' from the dropdown menu in the 'Who can send you friend requests?' section of the 'Privacy' page. Users should also limit who can find their Facebook profiles with their numbers and email addresses. There is an option at the bottom of the page to prevent search engines outside of Facebook from linking to Facebook profile.

4) Control access to Facebook Timeline

Facebook users can limit who gets to post things and see posts on their 'Timeline'. In 'Settings', go to 'Timeline and Tagging' and edit the sections users wish to lock down.

5) Block people

When a Facebook user blocks another Facebook user, the blocked user will not be able to see things that are posted on the person's Facebook 'Timeline', tag, invite to events or groups, start conversations or add as a friend. Users have to change the settings for blocking a user, or rather add in the 'Restricted' list. Users who are in 'Restricted' list can only see public posts and things shared on a mutual friend's 'Timeline'. However, blocking a user has to be done separately on Facebook 'Messenger'.

6) Review tags

One of Facebook's convenient privacy features is the ability to review posts users tagged in before they appear on users' 'Timeline'. Users should enable the 'Timeline review' controls in 'Timeline and Tagging' to control this.

7) Clean up applications

Users can view a list of all applications they have connected to their Facebook accounts by going to 'Settings' and 'Apps'. Users should do a regular housekeeping on applications especially those they no longer use. Users can also choose not to log into websites and applications with their Facebook accounts, by turning off 'Platform' in the same setting.

8) Change advertisement preferences

Users can view a list of everything Facebook thinks users have interest into and tinker with users' advertisement preferences by going to 'Settings' and 'Adverts'. More information is displayed on the desktop site than the application.

9) Download data

Facebook lets users download all of the data it has on its users, including the posts they share, messages and photos, advertisements that users click on and even the IP addresses that are logged when users log in or out of the site. There is a lot of information which users should download to ensure they do not over-share too much information on the social network.

\section{Malaysian Government's Initiatives}

Patti, Damiano and Bosco (2017) suggest that when it is critical to create awareness of ethical behaviour in social media, a national or supranational authority must play their roles effectively. Nobody is able to stop the data mining activity but a legal authority may create a clear boundary to be followed by all parties. A guideline must be developed to allow an ethical exploitation of the great potential of technologies. 


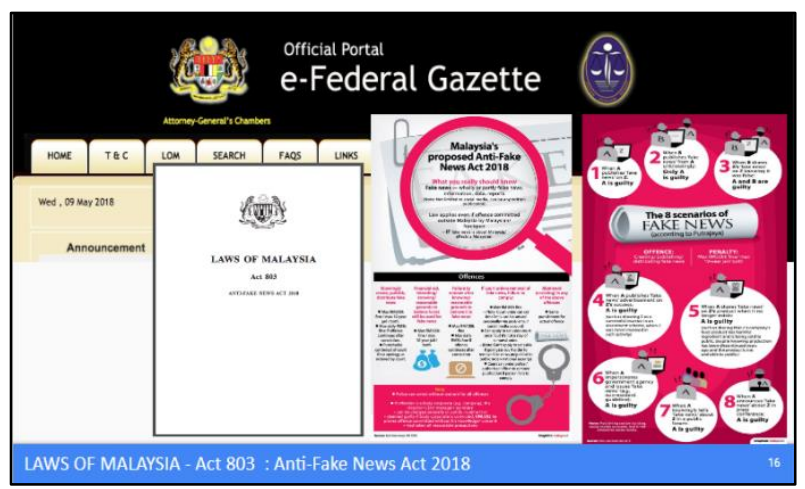

Figure 2: Official Portal for Anti-Fake News

Malaysian Government has taken initiatives to approve the Act 803 - Anti Fake News. The Government introduced this new legislation due to the issue of dissemination of fake news which is also a global problem, following the technological communication revolution, which is happening at a rapid pace. The bill, that will complement the existing provisions of the law, is aimed at protecting the public from fake news and, at the same time, ensuring that their rights to speech and expression under the Federal Constitution is respected. It expresses the government's commitment to address the dissemination of fake news due to the rapid and intensive growth of communication technology and regulates the dissemination of fake news in any medium of publication and it is not restricted to social media. The scope of this bill is extensive and exclusive to address offences pertaining to fake news thoroughly and effectively. Apart from a clear definition or illustration of what constitutes fake news, the bill also provides for punishment for those who fund the dissemination of fake news, not removing fake news when required, and others. At the same time, the bill also creates temporary measures to stem fake news while investigation and prosecution is being done.

While at the international level, a regulation of General Data Protection Regulation (GDPR) was issued by the European Commission, the European Parliament, and the Council of Ministers of the European Union (EU), for the purpose of strengthening and unifying data protection for people residing in the EU. Individual travelling to EU countries will also have to comply with this regulation. Despite all the advantages of doing business in Facebook as it is considered as open market (unlimited opportunity), users realise that it is the same time very risky. Users become fragile and very concern on leaked of personal details to third-parties without their consent. The objective of this regulation is also to harmonise the fragmented legacy legislation among EU member states.

\section{Conclusion}

This article shall make several conclusions from users' perspective. First, Facebook as a tool for social networking. Users should realise that Facebook may become a great tool for businesses, social interaction, research and knowledge sharing that offers many new exciting opportunities. And if government decides to ban Facebook and replace it with a new social media platform, these happy users will fight against the cause. It may create suspicious among citizens of the new platform that it will not promote freedom of speech and every news will be filtered. Worst of all, the people might feel that the government is trying to have a more stringent and tighter control where it benefits only the ruler. But many realised, Facebook can become harmful especially when users share too much of personal information (exposed to predators and luring criminal act) or sharing information from 
unreliable source (hoax, fake news, slanders). In no time, users are led down to a potential risk and greater danger.

Many users are aware of the danger and potential risks that may be exposed to them. However, they still find a lot of them tend to do this in response of excitement, happiness, even hatred. For example, parents are excited to share a video of their children dancing and performing in school. At the same time, parents share details like the school name which can be easily found via GPS technology in Google maps or Waze applications, and exposing their own children to threats.

Asking opinion of whether Facebook should ban due to this, this may impact user's objection and stress out that the ethical use of social media should be everybody's responsibility. Therefore, Facebook should not be blamed and banning the social media platform will not be a popular approach.

Meanwhile, in view of national interest, the amount of data shared on Facebook has started to raise concern and this number is not going to slow down. The existence of virtual agent (read Artificial Intelligent) that is collecting and processing these big data and transforming them into valuable information is an open secret. Data and information has become new commodity to be sold to third-parties for various purposes such as businesses, political view, and market trend.

The worst part is when the information contains sensitive data that becomes a threat to national security. Pictures, videos, images, location, control room and building of sensitive areas such as military base, airports, and government offices are some of the examples that can be name of. No idea of how much data has leaked into the funnel of information to be sold to other parties.

The attack at dawn in Pearl Harbour, 1940, was a big success as a result of many years of information leaked to Japan. That was before the era of IR 3.0, there was no Internet. Furthermore, the potential of threats does not only implicate a country but also economic and political stability. The government should consider to ban Facebook or alternatively to take proactive actions in order to mitigate the risk and prevent this potential danger.

The government should run analysis to identify risk and impact on national security. And the same time, launch a campaign to ensure users' readiness and increase the awareness. It is best to run a survey to measure feedback and perception of Malaysian Facebook users before and after the campaign. Alternatively, Malaysia government should offer and provide a secure channel for the new social media platform. Let the social media users to decide what is best for them and for the nation.

\section{Acknowledgement}

This article is financially supported by:

1. Faculty of Information Management, UiTM Selangor, Malaysia

2. Advanced Analytics Engineering Center (AAEC), UiTM Malaysia

\section{References}

American Academy of Matrimonial Lawyers (AAML). (2018). Huge Increase of Texts and App Evidence in Divorces Say Nation's Top Lawyers: Smart Phones and Other Wireless Devices Yielding Treasure Trove of Incriminating Information. http://aaml.org/about-theacademy/press/press-releases/divorce/huge-increase-texts-and-app-evidencedivorces-say-nat?page=4. Accessed 23 May 2018.

Nasmian, M., Yatin, S. F. M., Ismail, R., Saleh, S. H., Yunus, M. N., Isa, A. M., \& Paiman, M. J. 
INTERNATIONAL JOURNAL OF ACADEMIC RESEARCH IN BUSINESS AND SOCIAL SCIENCES Vol. 10, No. 11, 2020, E-ISSN: 2222-6990 @ 2020 HRMARS

(2020). Facebook - Face it or Phase Out. International Journal of Academic Research in Business and Social Sciencess, 10(11), 1-. 